\title{
ERRATUM
}

\author{
B. D. Reddy
}

\section{Erratum to: The role of dissipation and defect energy in variational formulations of problems in strain-gradient plasticity. Part 1: polycrystalline plasticity}

Published online: 8 November 2011

(C) Springer-Verlag 2011

Erratum to: Continuum Mech. Thermodyn. (2011) 23:527-549

\section{DOI 10.1007/s00161-011-0194-9}

Unfortunately, a paragraph in the published version of the article contained mistakes. The corrected version is printed below:

\subsection{Alternative forms for the dissipation}

\subsubsection{The Fleck-Willis quadratic form}

Paragraph 2 should read:

Following [10] a scalar stress quantity $\sigma_{\text {dis }}$ conjugate to $\dot{e}^{p}$ is defined in such a way that

$$
\sigma_{\text {dis }}^{2}=\Sigma_{\text {dis }}: \mathrm{D} \Sigma_{\text {dis }}
$$

where $D$ is the inverse of $A$ in the sense that $D(A \Gamma)=\Gamma$ and $A(D \Sigma)=\Sigma$. The identity $\Sigma_{\text {dis }}: \dot{\Gamma}=\left|\Sigma_{\text {dis }}\right| 2|\dot{\Gamma}|_{2}$ which follows from (2.32) and (2.33) is recovered as a special case by setting $A=\operatorname{diag}\left[\boldsymbol{I}_{1}, \ell_{d} \boldsymbol{I}_{2}\right]$, in which $\boldsymbol{I}_{1}$ and $\boldsymbol{I}_{2}$ are identity tensors of appropriate dimension. Then $\dot{e}^{p}=|\dot{\Gamma}|_{2}$ and $\sigma_{\mathrm{dis}}=\left|\Sigma_{\mathrm{dis}}\right|_{2}$. The yield function is

$$
\bar{f}\left(\sigma_{\text {dis }}\right)=\sigma_{\text {dis }}-\Sigma_{Y}\left(e^{p}\right) \leq 0
$$

and the associative flow law becomes

$$
\dot{\Gamma}=\lambda \frac{\partial \bar{f}}{\partial \Sigma_{\text {dis }}}=\lambda \frac{\mathrm{D} \Sigma_{\text {dis }}}{\sigma_{\text {dis }}}
$$

in which $\lambda=\dot{e}^{p}$, together with the complementarity relations $\lambda \geq 0,, \bar{f} \leq 0,, \lambda \bar{f}=0 \ldots \ldots$

Communicated by Andreas Öchsner.

The online version of the original article can be found under doi:10.1007/s00161-011-0194-9.

B. D. Reddy $(\varangle)$

Department of Mathematics and Applied Mathematics and Centre for Research in Computational and Applied Mechanics, University of Cape Town, 7701 Rondebosch, South Africa

Tel.: +27-21-6503787

Fax: +27-21-6852281

E-mail: daya.reddy@uct.ac.za 